Research of France. The proceedings have now been published as a well produced book with numerous illustrations and an index of authors though not of subjects. The 120 participants and their precise addresses are listed, and it is noteworthy that there was a considerable participation from Eastern Europe. There are four introductory lectures of which two are authoritatively surveying a particular technique. Red blood cell serology as a tool in general immunology is described by R. R. A. Coombs, and the principles and uses of immunochemistry are stated by P. Grabar. In an excellent didactic contribution T. H. J. Huisman compresses into 15 pages all there is known of the haemoglobin types of horse, cattle, sheep, and goat. A. Robertson discusses the relevance of our knowledge of biochemical polymorphisms in farm animals to their improvement. He considers that, at least in research, there is now a gradual overlapping of two kinds of genetic variation, that controlling quantitative characteristics, and that showing itself in the form of biochemical polymorphisms. The introductory part is followed by 12 specialised chapters, composed of contributions by several participants of the Conference, each of which has its own list of references, and is often followed by the account of a discussion. They deal with the blood groups and/or serum polymorphisms of cattle, sheep, horse, pig, dog, chicken and fish. A section on animal haemoglobins includes evidence for prenatal haemoglobins in cattle by D. O. Schmid and the description of an improved "fingerprinting" technique by G. Efremov. A chapter on milk proteins allows the conclusion that it is only a question of time that variants of casein will rival in number those of haemoglobin. Of particular interest to the geneticist are linkage studies such as observations on the relationship between the serum amylase system and blood group systems in pig by P. Brauner Nielsen. A group of workers from Warsaw tested sera from wisent and cattle and from hybrids, and found specific antibodies for red cell antigens of man, chicken, and coypu.

This book is a treasure trove of information. It summarises results in areas where substantial knowledge has already accumulated, and brings to attention single contributions which may represent a beginning of new fields of endeavour.

H. LeHmanN

Department of Biochemistry, University of Cambridge

\title{
HORMONES AND GENETIC VARIATION
}

ENDOCRINE GENETICS. S. G. Spickett. Cambridge University Press. 1967.

Endocrine Genetics is an account of a conference conceived and organised by the late Stuart G. Spickett who saw so clearly the urgent need for more collaboration between geneticists and physiologists. The self-confessed message of this book is that genetics provides a point of "articulation between the concepts of molecular biology and physiology".

The conference was subdivided into three main sections: the first being devoted to the molecular mode of action of hormones, and being followed by discussion on genetic variation in endocrine function, and finally on quantitative aspects of genetic variation. The most controversial section in the book deals with puffing in dipteran chromosomes and the mode of 
control of certain puffs by ecdysone. Both Kroeger and Karlson extrapolate so far from their results to opposing theories that they reach positions from which they can only argue with each other.

After all the lectures an edited discussion is published which sometimes, as after the lecture by Karlson, leaves the reader uncomfortably in the air, but generally serves to illuminate the material.

The section which deals with the phylogeny of hormone species, and metabolic faults in hormone synthesis and their results, illustrates how basic physiological information can be obtained by comparing inherited defects such as changes in the structure of hormone molecules and investigating strain differences.

The final section illustrates that quantitative characteristics hitherto thought of as being beyond other than biometrical analysis may be open to deeper investigation, and sometimes are genetically much less complicated than was feared (Spickett, see Thoday). A very lucid account by Huntley analyses four carefully chosen examples of quantitative characters in man and shows how variation in each can reasonably be apportioned between that due to genetic and environmental causes.

The book as a whole provides a stock of examples where the study of heredity and segregation has provided useful physiological information about the wild type or atypical individual. This approach to physiological problems is upheld in Thoday's final chapter in the book. Thoday points out that by a process of physiological compensation genetically quite different strains function normally. Comparative study of such strains can illuminate the relationship in the individual of such factors as hormone concentration and activity of secreting gland (Spickett, Shire and Stewart). Variation between healthy laboratory strains can be the kind of research tool previously achieved only through the investigation of pathological examples.

The material in the book justifies the novel title, and the scientific thesis of its editor. It will make useful and interesting reading for anyone interested in endocrinology or developmental and physiological genetics.

\section{P. LAWRENGE \\ Department of Genetics, University of Cambridge}

\section{NEW DRUGS AND CLINICAL MEDICINE}

\section{DRUG RESPONSES IN MAN. Ed. G. Wolstenholme and R. Porter. J. \& A. Churchill} London. 1967.

This book is an account of the proceedings of a symposium on drug responses in man which was held under the auspices of the Ciba Foundation. The purpose of the meeting was to discuss the unexpected and unpredicted responses that occur when new drugs are brought into widespread clinical use. These unanticipated effects may include favourable and useful responses as well as undesirable or disastrous side-effects. Consideration of carcinogenic and teratogenic side-effects was specifically excluded.

Anomalous responses to new drugs in man can be of two kinds: those which can be detected to a greater or lesser extent in all treated individuals, 